\title{
Effects of 4-week very-high-fructose/glucose diets on insulin sensitivity, visceral fat and intrahepatic lipids: an exploratory trial
}

\author{
Guenther Silbernagel ${ }^{1}$, Juergen Machann ${ }^{2}$, Susanne Unmuth ${ }^{1}$, Fritz Schick ${ }^{2}$, Norbert Stefan ${ }^{1}$, \\ Hans U. Häring ${ }^{1}$ and Andreas Fritsche ${ }^{1_{*}}$ \\ ${ }^{1}$ Division of Endocrinology, Diabetology, Nephrology, Vascular Disease and Clinical Chemistry, Department of Internal \\ Medicine, Eberhard-Karls-University Tübingen, Otfried-Müller-Straße 10, 72076 Tübingen, Germany \\ ${ }^{2}$ Section on Experimental Radiology, Department of Diagnostic Radiology, Eberhard-Karls-University Tübingen, \\ Hoppe-Seyler-Straße 3, 72076 Tübingen, Germany
}

(Received 5 July 2010 - Revised 6 December 2010 - Accepted 9 December 2010 - First published online 14 March 2011)

\section{Abstract}

An increasing amount of fructose in the diet is suggested to play a causal role in the pathogenesis of the metabolic syndrome, type 2 diabetes and fatty liver. Our aim was to investigate and compare the effects of very high fructose and very high glucose in hyperenergetic diets on glucose and lipid metabolism and on fat depots in healthy humans. We conducted an exploratory, prospective, randomised, singleblinded, intervention trial. Participants in addition to a balanced weight-maintaining diet received $150 \mathrm{~g}$ of fructose or glucose/d for 4 weeks. Insulin sensitivity was estimated from oral glucose tolerance tests. Visceral and subcutaneous abdominal fat was determined with MRI. Liver fat and intramyocellular lipids of the tibialis anterior muscle were measured with ${ }^{1} \mathrm{H}$ magnetic resonance spectroscopy. A total of twenty healthy subjects (fructose group $n 10$ and glucose group $n 10$; twelve males and eight females) completed the study. They had a mean age of 30.5 (SEM $2 \cdot 0$ ) years and a mean BMI of $25.9($ SEM 0.5$) \mathrm{kg} / \mathrm{m}^{2}$. Insulin sensitivity appeared to decrease both in the fructose and glucose groups. TAG markedly increased in the fructose group. No strong alterations or treatment effects were found for liver fat, visceral fat, subcutaneous abdominal fat and intramyocellular lipids of the tibialis anterior muscle. In conclusion, the effects of very high fructose and very high glucose in hyperenergetic diets on glucose metabolism and body fat composition were not different in the healthy participants of the present study. However, elevation of plasma TAG seemed to be fructose-specific.

\section{Key words: Dietary fructose: Liver fat: Visceral fat: Insulin sensitivity: Lipid metabolism}

Intake of added sweeteners, essentially of table sugar and high-fructose corn syrup, is markedly increased today compared with the $1960 \mathrm{~s}^{(1,2)}$. Table sugar consists of sucrose which is a disaccharide composed of fructose and glucose. Similarly, high-fructose corn syrup contains about $42-55 \%$ of fructose and about $45-58 \%$ of glucose in monosaccharide form. Several epidemiological studies have related high dietary fructose intake to prevalent obesity and overweightassociated diseases such as the metabolic syndrome, type 2 diabetes and fatty liver. In addition, overconsumption of fructose has been shown to cause obesity in rats ${ }^{(1-9)}$.

There are important differences between fructose and glucose metabolism. Fructose, after intestinal uptake, is mainly removed from the blood stream by the liver in an insulinindependent manner. It is used for intrahepatic production of glucose, fatty acids or lactate. Newly synthesised NEFA are exported from the liver in the form of VLDL-TAG ${ }^{(1,3,10)}$. In contrast, glucose, once absorbed, is predominantly transported to peripheral tissues, where it is taken up into cells mediated via insulin.

The aim of the present exploratory study was to investigate and compare the effects of very high fructose and very high glucose in hyperenergetic diets on (1) intrahepatic- and intramyocellular lipids (IMCL), (2) visceral fat and (3) insulin resistance and plasma lipids. We studied young to middle-aged, normal- and overweight individuals and used a randomised design.

\section{Experimental methods}

\section{Study design and diet}

The TUebingen Fructose Or Glucose (TUFROG) study is an exploratory, prospective, randomised, single-blinded, outpatient, intervention study. Inclusion criteria were age $20-50$ years, BMI $20-35 \mathrm{~kg} / \mathrm{m}^{2}$, physical health and not more than

Abbreviations: IMCL, intramyocellular lipid; OGTT, oral glucose tolerance test; TUFROG, TUebingen Fructose Or Glucose.

*Corresponding author: Professor Dr A. Fritsche, fax + 497071 292784, email andreas.fritsche@med.uni-tuebingen.de 
$1 \mathrm{~h}$ sports/week. Exclusion criteria were pregnancy, any relevant illness (i.e. diabetes, dyslipidaemia, endocrine disease, coronary artery disease, malignancy, gastrointestinal disease and psychological disease), fructose intolerance, medication, metal implants (e.g. pacemaker, metal heart valve), regular alcohol consumption $\geq 10 \mathrm{~g} / \mathrm{d}$ and claustrophobia. The participants received $150 \mathrm{~g}(2512 \mathrm{~kJ}(600 \mathrm{kcal}) / \mathrm{d})$ of fructose or $150 \mathrm{~g}$ of glucose $(2512 \mathrm{~kJ}(600 \mathrm{kcal}) / \mathrm{d})$ for 4 weeks. They were not told whether they received fructose or glucose. The sugar was provided in identical plastic packs of $50 \mathrm{~g}$ and had to be dissolved in water $(50 \mathrm{~g}$ sugar in $250 \mathrm{ml}$ water). The participants were instructed to consume the sugar in addition to a balanced weight-maintaining diet ( $50 \%$ carbohydrates, $35 \%$ fat and 15\% protein). Fructose or glucose was ingested three times a day (morning, midday and evening) with the main meals. Dietary counselling was provided by an experienced dietitian according to the guidelines of the German Society of Nutrition. There were three visits at the study laboratory: a screening examination at the beginning of the study and visits 1 and 2 (clinical examination, blood withdrawal, oral glucose tolerance test (OGTT), MRI and magnetic resonance spectroscopy) at 2 and 6 weeks after the screening examination, respectively. Moreover, study participants were contacted via telephone at day 14 of the intervention to determine whether the fructose or glucose was well tolerated and regularly consumed. At the screening examination, the decision about inclusion of a participant was made by a physician based on the inclusion-exclusion criteria mentioned above. Furthermore, participants had a fructose test drink and received dietary counselling for $1 \mathrm{~h}$. After a run-in phase of 2 weeks between screening examination and visit 1 in which the subjects were instructed to keep an isoenergetic diet (50\% carbohydrates, 35\% fat and $15 \%$ protein), the participants were randomised to the fructose or glucose intervention group, and dietary counselling for $1 \mathrm{~h}$ was repeated. Restricted randomisation (blocking) was performed with a computerised random number generator. We did not use stratification. Random number generation was performed by an information technology manager who was not clinically involved in the study. The random allocation sequence was concealed from the physicians enrolling the study participants. The information whether a participant had to be allocated to the glucose or fructose intervention was provided by a coordinator according to the randomisation sequence at visit 1 . The laboratory personnel and the radiologists (J. M. and F. S., quantification of the body fat compartments) were blinded to the type of intervention. The other health care providers/data collectors/outcome adjuncators/ data analysts knew about the type of intervention after randomisation had been performed ${ }^{(11)}$. We aimed to assess compliance with the dietary prescription by close telephone contact. The participants were instructed to immediately inform the investigators in case of problems with the intake of fructose or glucose. For this purpose, they were provided a calling card. Furthermore, compliance was evaluated by interview at visits 1 and 2 . In addition, the subjects were asked to fill out food intake records on $3 \mathrm{~d}$ in each week of the study. Food intake records were incomplete in four participants. The data on the remaining sixteen subjects were analysed for energy intake and composition of the diet (percentage of carbohydrate, fat and protein) by a trained dietitian using DGE $\mathrm{PC}^{\circledR}$ software (GOE $\mathrm{mbH}$, Linden, Germany; www.goe-software.de). The study was approved by the local ethics committee and was conducted in accordance with the Declaration of Helsinki. Informed written consent was obtained from all participants. Recruitment began in April 2008.

\section{Body composition and body fat distribution}

Total body fat was measured by the bioelectrical impedance method (RJL, Detroit, MI, USA) ${ }^{(12)}$. Subcutaneous abdominal fat and visceral adipose tissue were measured by MRI applying an axial T1-weighed fast spin echo technique with a $1.5 \mathrm{~T}$ whole-body MR imager (Magnetom Sonata; Siemens Healthcare, Erlangen, Germany) in the complete abdominal region, ranging from the head of the femur to the head of the humerus. Slice thickness was $10 \mathrm{~mm}$, with a gap of $10 \mathrm{~mm}$, between subsequent slices. Approximately thirty-five slices were recorded for each volunteer, depending on size ${ }^{(13)}$.

\section{Quantitative analysis of liver fat and intramyocellular lipids}

Liver fat as well as IMCL of the tibialis anterior muscle was determined by localised proton magnetic resonance spectroscopy, applying a single-voxel stimulated echo acquisition mode (STEAM) technique with short echo time as described previously $^{(14,15)}$.

\section{Oral glucose tolerance test}

We performed standard $75 \mathrm{~g}$ OGTT after a $10 \mathrm{~h}$ overnight fast. Venous plasma samples were obtained at 0, 30, 60, 90 and 120 min for the determination of plasma glucose and insulin.

\section{Analytical procedures}

Blood glucose was determined using a bedside glucose analyser based on a glucose-oxidase method (Yellow Springs Instruments, Yellow Springs, CO, USA). Insulin was analysed by microparticle enzyme immunoassay (Abbott Laboratories, Tokyo, Japan). Total, HDL- and LDL-cholesterol concentrations were measured with a standard colorimetric method on a Bayer analyser (Bayer Health Care, Leverkusen, Germany), and TAG and NEFA were quantified with an enzymatic method (Wako Chemicals, Neuss, Germany). Uric acid was measured with an enzymatic method on the automatic ADVIA 1650 analyser (Siemens Medical Solutions Diagnostics). All analytical procedures were performed about $10 \mathrm{~min}$ after blood withdrawal at the central laboratory facility of the University Hospital Tübingen, Germany.

\section{Calculations}

Energetic requirements were calculated using sex-specific equations presented by Mifflin et $a l .{ }^{(16)}$ : males - resting energy $\quad$ expenditure $=9.99 \times$ weight $-4.92 \times$ age $+6.25 \times$ 
height +5 ; females - resting energy expenditure $=9.99 \times$ weight $-4.92 \times$ age $+6.25 \times$ height -161 . Total energy expenditure was computed by multiplication of the resting energy expenditure with a physical activity level of 1.6 $(\leq 1 \mathrm{~h} \text { of } \text { sports/week })^{(17)}$. Insulin sensitivity was estimated from the OGTT as proposed by Matsuda \& DeFronzo ${ }^{(18)}$ :

$$
\mathrm{ISI}_{\mathrm{est}}=10000 / \sqrt{\left(\mathrm{Ins}_{\text {mean }} \times \mathrm{Gluc}_{\text {mean }} \times \mathrm{Ins}_{0} \times \mathrm{Gluc}_{0}\right)} .
$$

Furthermore, we used the homeostasis model assessment of insulin resistance $=\mathrm{Ins}_{0} \times \mathrm{Gluc}_{0} / 22 \cdot 5^{(19)}$.

\section{Statistical analysis}

The clinical and biochemical characteristics and estimated energy requirements of the study participants are presented as means with their standard errors separately for men and women. Comparisons of the baseline characteristics, estimated energy requirements, and dietary intake between the fructose and glucose groups were performed with the $t$ test or the $\chi^{2}$ test for continuous and categorical variables, respectively. Changes in metabolic parameters in response to the 4-week high-hexose diets were studied with the two-sided paired samples $t$ test. For body-weight gain and body-fat gain, we used the one-sided paired samples $t$ test because both were expected to rise with extra energy. Data that were not normally distributed (Shapiro-Wilk $W$ test) were transformed logarithmically (base e). ANCOVA was used to compare the changes in metabolic parameters (e.g. change in liver fat between visits 1 and 2) between the fructose and glucose intervention groups, with study group as the main factor and the metabolic parameter of interest at baseline (e.g. liver fat at visit 1) as covariate (two-sided tests). To estimate the treatment effect, differences in least-squares means and the corresponding $95 \% \mathrm{CI}$ were calculated based on the ANCOVA models ${ }^{(11)}$. Due to the exploratory nature of the present study, the $P$ values were not corrected for multiple testing. The JMP statistical software package 4.0 (SAS Institute, Cary, NC, USA) was used.

\section{Results}

\section{Subjects}

A total of thirty-four individuals were screened (Fig. 1) . Of this cohort, five subjects did not meet the inclusion criteria and four subjects declined participation. The remaining twenty-five subjects were randomised to either the fructose ( $n$ 12) or the glucose ( $n$ 13) intervention. There were two and three dropouts in the fructose and glucose groups, respectively (Fig. 1).

\section{Baseline characteristics, energy requirements and diet}

A total of twelve males and eight females completed the study. They had a mean age of $30 \cdot 5$ (SEM $2 \cdot 0)$ years and a mean BMI of $25.9($ SEM 0.5$) \mathrm{kg} / \mathrm{m}^{2}$. The estimated mean resting and daily energy expenditures and the portions of the hexose supplementation compared with the participants' daily energy requirements were not different in the fructose and glucose intervention groups (Tables 1 and 2). Energy intake and the composition of the diet (percentage of carbohydrate, fat and protein) during the run-in phase and during the intervention period were not different in the fructose and glucose intervention groups either (all $P>0 \cdot 2$ ).

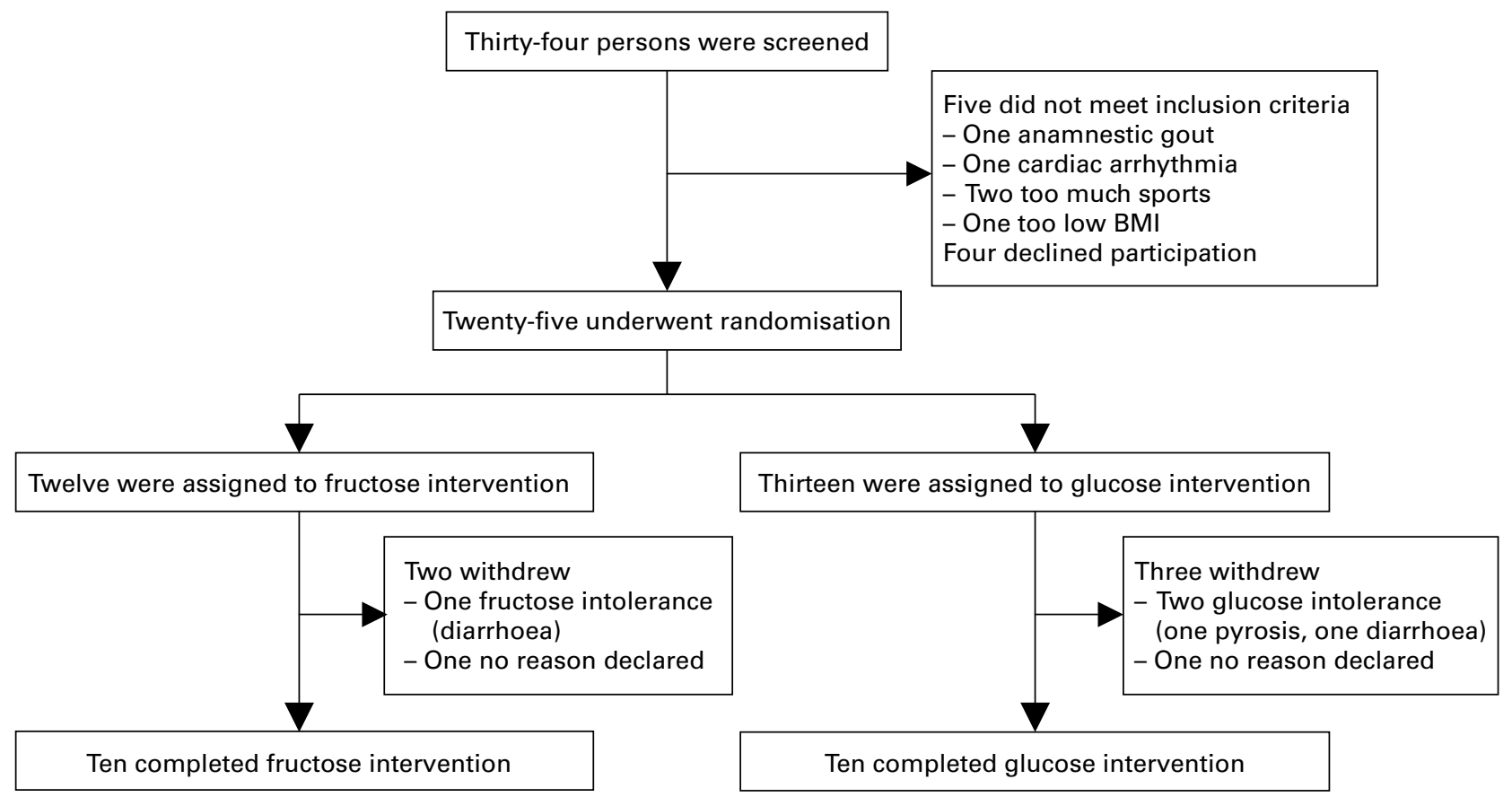

Fig. 1. Enrolment of the participants and completion of the study. 
Table 1. Baseline characteristics of the study participants

(Mean values with their standard errors)

\begin{tabular}{|c|c|c|c|c|c|c|c|c|c|}
\hline & \multicolumn{4}{|c|}{ Fructose group } & \multicolumn{4}{|c|}{ Glucose group } & \multirow{3}{*}{$\begin{array}{c}P^{*} \\
0.359\end{array}$} \\
\hline & \multicolumn{2}{|c|}{ Males $(n 7)$} & \multicolumn{2}{|c|}{ Females $(n 3)$} & \multicolumn{2}{|c|}{ Males $(n 5)$} & \multicolumn{2}{|c|}{ Females $(n 5)$} & \\
\hline & Mean & SEM & Mean & SEM & Mean & SEM & Mean & SEM & \\
\hline Age (years) & $32 \cdot 6$ & $3 \cdot 4$ & $33 \cdot 3$ & $7 \cdot 0$ & $28 \cdot 6$ & $2 \cdot 3$ & $27 \cdot 8$ & $5 \cdot 1$ & 0.260 \\
\hline Height $(\mathrm{cm})$ & 179 & 3 & 173 & 5 & 180 & 3 & 171 & 2 & 0.611 \\
\hline Weight (kg) & 82.5 & 3.4 & $75 \cdot 3$ & 4.9 & 82.5 & 3.5 & 78.9 & 3.4 & 0.920 \\
\hline BMI $\left(\mathrm{kg} / \mathrm{m}^{2}\right)$ & $25 \cdot 6$ & 0.8 & $25 \cdot 4$ & $1 \cdot 7$ & $25 \cdot 4$ & 1.0 & $27 \cdot 0$ & $1 \cdot 1$ & 0.507 \\
\hline Waist $(\mathrm{cm})$ & $86 \cdot 9$ & 3.0 & $79 \cdot 3$ & $4 \cdot 8$ & $84 \cdot 2$ & 3.7 & $87 \cdot 6$ & $5 \cdot 2$ & 0.754 \\
\hline Total body fat $(\mathrm{kg})$ & $18 \cdot 26$ & 2.56 & 29.99 & $4 \cdot 31$ & $16 \cdot 22$ & 1.77 & 32.38 & $3 \cdot 76$ & 0.566 \\
\hline Subcutaneous abdominal fat $(\mathrm{kg}) \dagger$ & 9.34 & 1.94 & $9 \cdot 50$ & 1.50 & $8 \cdot 28$ & $1 \cdot 10$ & $13 \cdot 10$ & 1.52 & 0.491 \\
\hline Visceral adipose tissue $(\mathrm{kg}) \dagger$ & $2 \cdot 75$ & 0.53 & 0.86 & 0.14 & 2.62 & 0.36 & 1.88 & 0.49 & 0.970 \\
\hline Liver fat (\% signal) & 1.54 & 0.39 & 0.81 & $0 \cdot 10$ & 1.92 & 0.27 & 1.25 & 0.41 & 0.417 \\
\hline$I M C L_{\text {tibialis anterior }}$ (arbitrary units) $\ddagger$ & 3.09 & 0.42 & 5.57 & 0.78 & 3.98 & 0.38 & 4.47 & 0.94 & 0.634 \\
\hline Systolic blood pressure $(\mathrm{mmHg})$ & 125 & 3 & 108 & 6 & 115 & 6 & 113 & 6 & 0.278 \\
\hline Diastolic blood pressure $(\mathrm{mmHg})$ & 81 & 3 & 72 & 6 & 78 & 4 & 72 & 3 & 0.411 \\
\hline Fasting glucose $(\mathrm{mmol} / \mathrm{l})$ & 4.79 & 0.11 & $4 \cdot 87$ & 0.24 & 4.89 & 0.08 & 4.90 & $0 \cdot 12$ & 0.524 \\
\hline Fasting insulin (pmol/l) & 36 & 7 & 67 & 37 & 44 & 7 & 57 & 11 & 0.310 \\
\hline Insulin sensitivity (arbitrary units)§ & $20 \cdot 4$ & 4.5 & $18 \cdot 4$ & 8.5 & $16 \cdot 4$ & $2 \cdot 2$ & 14.2 & $2 \cdot 8$ & 0.297 \\
\hline HOMA (arbitrary units) & 1.30 & 0.24 & $2 \cdot 54$ & 1.52 & 1.58 & 0.24 & 2.09 & 0.42 & 0.306 \\
\hline Total cholesterol $(\mathrm{mg} / \mathrm{l})$ & 1790 & 90 & 1670 & 120 & 1800 & 110 & 1700 & 110 & 0.948 \\
\hline LDL-cholesterol (mg/l) & 1070 & 50 & 1010 & 130 & 1130 & 140 & 1030 & 130 & 0.824 \\
\hline HDL-cholesterol (mg/l) & 540 & 40 & 540 & 40 & 490 & 30 & 570 & 40 & 0.834 \\
\hline TAG $(\mathrm{mg} / \mathrm{l})$ & 870 & 150 & 650 & 40 & 1080 & 170 & 880 & 130 & 0.236 \\
\hline NEFA $(\mu \mathrm{mol} / \mathrm{l})$ & 585 & 105 & 776 & 135 & 495 & 62 & 651 & 90 & 0.617 \\
\hline Uric acid (mg/l) & 58 & 6 & 46 & 2 & 62 & 5 & 53 & 6 & 0.642 \\
\hline
\end{tabular}

IMCL, intramyocellular lipids; HOMA, homeostasis model assessment

${ }^{*} P$ values were significantly different between the fructose and glucose groups (two-sided $t$ test or the $\chi^{2}$ test for continuous and categorical variables, respectively).

†Fructose group: men $n 6$ and women $n 2$; glucose group: men $n 5$ and women $n 5$.

‡Fructose group: men $n 5$ and women $n 3$; glucose group: men $n 4$ and women $n 5$.

$\S$ Estimated according to Matsuda.

\section{Changes in body weight, fat depots and blood pressure in} response to very-high-fructose or very-high-glucose diet

Body weight appeared to increase in the glucose but not in the fructose intervention group. The treatment effect of glucose and fructose on weight change was not different (Table 3). We did not observe strong alterations in total fat mass, visceral and subcutaneous abdominal fat, liver fat, IMCL of the tibialis anterior muscle and blood pressure in either group. Treatment effects of fructose and glucose on the changes in total fat mass, visceral and subcutaneous abdominal fat, liver fat, IMCL of the tibialis anterior muscle and blood pressure were not different (Table 3; see the supplementary figure available online at http://www.journals.cambridge.org/bjn).

\section{Changes in glucose and lipid metabolism and in plasma} uric acid in response to very-high-fructose or very-highglucose diet

Insulin sensitivity estimated according to Matsuda seemed to decrease both in the fructose and glucose intervention groups. These results were supported by the changes in the homeostasis model assessment index (Table 4; see the supplementary figure, available online at http://www.journals. cambridge.org/bjn). We did not observe pronounced changes in plasma NEFA, total cholesterol, LDL-cholesterol, HDLcholesterol and uric acid in either group (Table 3; see the supplementary figure, available online at http://www.journals. cambridge.org/bjn). Plasma TAG markedly increased in the fructose group with a trend towards a difference between interventions (Table 4; see the supplementary figure, available online at http://www.journals.cambridge.org/bjn).

Table 2. Energy requirements of the study participants (Mean values with their standard errors)

\begin{tabular}{|c|c|c|c|c|c|}
\hline & \multicolumn{2}{|c|}{ Fructose group } & \multicolumn{2}{|c|}{ Glucose group } & \multirow[b]{2}{*}{$P^{\star}$} \\
\hline & Males & Females & Males & Females & \\
\hline \multicolumn{6}{|c|}{$\begin{array}{l}\text { Resting energy expenditure } \\
\text { kJ }\end{array}$} \\
\hline Mean & 7494 & 6293 & 7595 & 6527 & 0.827 \\
\hline SEM & 193 & 402 & 214 & 159 & \\
\hline \multicolumn{6}{|l|}{ kcal } \\
\hline Mean & 1790 & 1503 & 1814 & 1559 & \\
\hline SEM & 46 & 96 & 51 & 38 & \\
\hline \multicolumn{6}{|c|}{$\begin{array}{l}\text { Daily energy expenditure } \\
\text { kJ }\end{array}$} \\
\hline Mean & 11995 & 10069 & 12150 & 10446 & 0.827 \\
\hline SEM & 310 & 645 & 339 & 255 & \\
\hline \multicolumn{6}{|l|}{ kcal } \\
\hline Mean & 2865 & 2405 & 2902 & 2495 & \\
\hline SEM & 74 & 154 & 81 & 61 & \\
\hline \multicolumn{6}{|c|}{ Fructose supplementation† } \\
\hline Mean & $21 \cdot 0$ & $25 \cdot 2$ & - & - & - \\
\hline SEM & 0.5 & $1 \cdot 7$ & - & - & \\
\hline \multicolumn{6}{|c|}{ Glucose supplementation† } \\
\hline Mean & - & - & $20 \cdot 7$ & $24 \cdot 1$ & - \\
\hline SEM & - & - & 0.6 & 0.6 & \\
\hline
\end{tabular}

${ }^{*} P$ value for difference between the fructose and glucose groups (two-sided $t$ test). $\dagger$ Expressed as a percentage of daily energy expenditure (calculated from individual patient data). 


\section{Discussion}

The main findings of the present study in young to middleaged healthy subjects were (1) 4 weeks of very high fructose and very high glucose in hyperenergetic diets did not markedly increase liver fat, visceral fat and IMCL of the tibialis anterior muscle. (2) Treatment effects of glucose and fructose on the changes in liver fat, visceral fat and IMCL of the tibialis anterior muscle were not different. (3) Both very high fructose and very high glucose in hyperenergetic diets appeared to induce a decrease in insulin sensitivity with no difference between interventions. (4) Very high fructose intake but not very high glucose intake caused an elevation of plasma TAG. Of relevance, the alterations in metabolic parameters induced by both very high fructose and very high glucose in hyperenergetic diets were within the physiological range.

A meta-analysis has demonstrated that the effects of fructose intake on glucose and lipid metabolism are dose-dependent $^{(20)}$. Daily consumption of more than $50 \mathrm{~g}$ of fructose is suggested to be relevant in the pathogenesis of the metabolic syndrome ${ }^{(21)}$. Fructose intake of more than $100 \mathrm{~g} / \mathrm{d}$ is regarded as very high. Participants of the TUFROG study in addition to a balanced diet were administered $150 \mathrm{~g}$ of fructose or glucose/ $\mathrm{d}$ for 4 weeks. This large amount was chosen to metabolically challenge the organism. Consequently, the present results do not reflect the metabolic effects of moderate monosaccharide intake in 'real life'.

In agreement with previous studies, very high fructose intake was associated with a marked increase in plasma TAG, most probably caused by an up-regulation of hepatic de novo lipogenesis and TAG secretion and a decreased clearance of VLDL-TAG ${ }^{(20-26)}$. On the contrary, NEFA were not strongly altered during the 4 weeks of the very-high-fructose or -glucose diet.

Our main objective was to investigate and compare the effects of very-high-fructose and very-high-glucose diets on hepatic lipid content and insulin resistance. An earlier study did not report an increase in ectopic lipid deposition in seven young healthy males receiving a hyperenergetic fructose diet $(1.5 \mathrm{~g} / \mathrm{kg}$ body weight per $\mathrm{d})$ for 4 weeks ${ }^{(23)}$. However, in three very recent studies, $7 \mathrm{~d}$ hyperenergetic fructose diets $(3.5 \mathrm{~g} / \mathrm{kg}$ fat-free mass per d) were associated with an increase in intrahepatic lipids again in healthy males (partly offspring of patients with type 2 diabetes) and particularly when combined with saturated fat ${ }^{(25-27)}$. Due to the availability of a control group receiving a very-high-glucose diet, it was possible to specifically address the difference between the effects of glucose and fructose on liver fat. Interestingly, the treatment effect of very high fructose and very high glucose in hyperenergetic diets on the relatively modest changes in liver fat was not different in participants of the TUFROG study. This finding in a cohort of males and females extends the results of a recently published study, which has been performed in males only ${ }^{(26)}$. The data suggest that at least in healthy subjects, fructose and glucose have no majorly different impact on hepatic lipid content.

Both very high fructose and very high glucose in hyperenergetic diets appeared to induce a decrease in insulin sensitivity

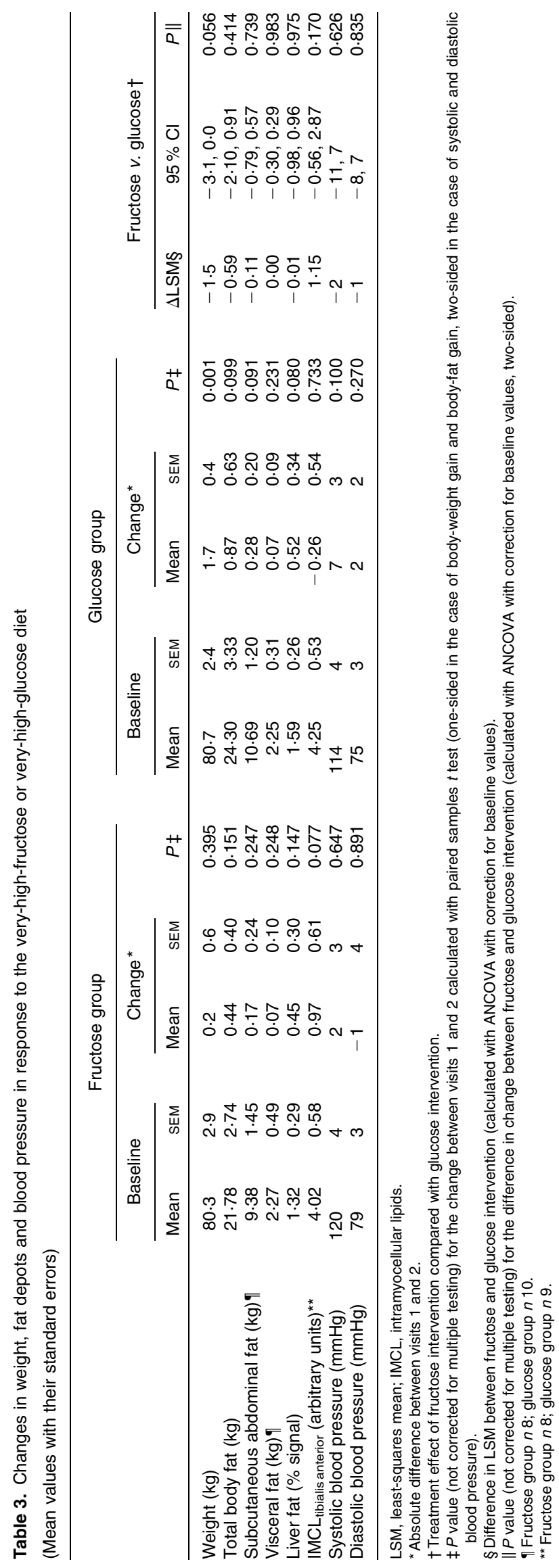


estimated from the OGTT in participants of the TUFROG study. Several previous studies have addressed the effect of fructose intake on insulin sensitivity ${ }^{(22-26,28)}$. In eight young healthy subjects, addition of $250 \mathrm{~g}$ of fructose per day to the usual diet continued for 1 week was accompanied by a significant reduction of insulin sensitivity ${ }^{(28)}$. A very-high-glucose diet $(250 \mathrm{~g} / \mathrm{d})$ did not cause significant changes in insulin sensitivity in the present study ${ }^{(28)}$. Another study in seven healthy males with a cross-over design reported that a $6 \mathrm{~d}$ hyperenergetic fructose diet ( $3 \mathrm{~g} / \mathrm{kg}$ body weight per $\mathrm{d})$ was associated with a decrease in hepatic and adipose tissue insulin sensitivity $^{(22)}$. Furthermore, a $7 \mathrm{~d}$ hyperenergetic fructose regimen ( $3.5 \mathrm{~g}$ fructose $/ \mathrm{kg}$ fat-free mass per $\mathrm{d})$ induced hepatic insulin resistance in a cohort of twenty-four healthy young males (partly offspring of subjects with type 2 diabetes) compared with an isoenergetic diet in a cross-over design ${ }^{(25)}$. Likewise, $7 \mathrm{~d}$ hyperenergetic fructose or glucose interventions $(3.5 \mathrm{~g} / \mathrm{kg}$ fat-free mass per $\mathrm{d}$ ) induced an increase in hepatic glucose output $v$. an isoenergetic control diet in a cross-over study in eleven healthy males ${ }^{(26)}$. In contrast, insulin sensitivity remained unchanged in a study in seven young healthy males after a 4-week hyperenergetic fructose diet $(1.5 \mathrm{~g} / \mathrm{kg}$ body weight per d) compared with an isoenergetic balanced diet using a longitudinal design ${ }^{(23)}$.

Unlike a recent trial by Stanhope $e t$ al. ${ }^{(24)}$, a very-high-fructose diet did not induce visceral obesity in the TUFROG collective. This may be due to the fact that participants of the TUFROG study were younger and had a lower BMI and therefore less metabolic risk. In addition, the study by Stanhope et al. had a longer duration of intervention (10 v. 4 weeks). Furthermore, the subjects consuming fructose in the study by Stanhope et al. ${ }^{(24)}$ gained a significant amount of body weight and body fat.

Body weight did not increase during fructose intervention in our cohort. This observation has also been made by Lê et $a l .{ }^{(23)}$. Bray et $a l .{ }^{(3)}$ initially raised the hypothesis that fructose may be related to obesity. This possible relationship has been suggested to be accounted for by the fact that fructose consumption does not provoke endogenous secretion of leptin ${ }^{(24)}$. Clinical studies investigating the implications of fructose on food intake are controversial ${ }^{(29,30)}$.

Fructose-induced hyperuricaemia has been hypothesised to be a causal factor in the pathogenesis of the metabolic syndrome $^{(31)}$. However, we did not observe an increase in the plasma uric acid concentration in the fructose group.

It has been reported that the increase in plasma TAG and the decrease in insulin sensitivity in response to high dietary fructose intake were only apparent in males ${ }^{(32,33)}$. The sample size of the present study was too small to investigate possible differences in the metabolic effects of fructose between males and females.

The main limitation of the present study is that we performed multiple tests, which would require a strict correction, e.g. Bonferroni with a conservative significance level of $P \leq 0.001$. Our approach was to clearly declare the study as exploratory only. Therefore, the findings have observational character and will definitely need to be reproduced and confirmed or challenged in larger cohorts in order to achieve a 
higher level of evidence. Furthermore, the TUFROG study was performed in an outpatient setting, which does not allow precise assessment of the compliance with the dietary instructions and with the intake of fructose or glucose. Nevertheless, the marked increase in plasma TAG in response to a very-highfructose diet suggests that the bulk of carbohydrate supplementation was also ingested in the fructose intervention group. We also used a randomised single-blinded design to reduce confounding due to malcompliance. It represents another limitation of the TUFROG study that the number of participants was relatively small. However, the sample size was similar or even larger compared with previous highly recognised studies in the field ${ }^{(23)}$. Of note, one would have to include 500 subjects (PS power and sample size calculations; biostat.mc.vanderbilt.edu) to detect a significant difference in the change of liver fat content of $0.07 \%$ signal between the glucose and fructose groups. It also has to be mentioned that MRI data were available for the trunk only (visceral fat and subcutaneous abdominal fat). The bioelectric impedance analysis was used for the quantification of the whole body fat, which may cause imprecision. Finally, our findings are restricted to young to middle-aged healthy individuals at low metabolic risk.

In summary, our data suggest that very high fructose and very high glucose in hyperenergetic diets do not have different effects on insulin resistance and hepatic lipid content. However, the conclusions drawn from the present small exploratory study need to be validated in larger cohorts.

\section{Acknowledgements}

All authors participated in the design of the study. S. U. and G. S. were responsible for the recruitment of the participants and performed the OGTT. The fat depots were quantified by J. M. and F. S. Data analysis was performed by A. F., S. U. and G. S. The manuscript was written by G. S. and A. F., and was critically revised by J. M., F. S., N. S. and H. U. H. All authors read and approved the manuscript. We thank all study participants for their cooperation. Furthermore, we gratefully acknowledge the help and excellent technical assistance of A. Bury, M. Graf, B. Horrer, E. Kollmar, S. Kümmerle, H. Luz and A. Vosseler. The study was supported by a grant from the German Research Foundation (KFO 114/2) and a grant (grant no. $4 \mathrm{AI}$ ) from the Zentrum Ernährungsmedizin Tübingen-Hohenheim. Funding did not include industrial sponsorship. The authors have no conflict of interest to declare.

\section{References}

1. Tappy L \& Lê KA (2010) Metabolic effects of fructose and the worldwide increase in obesity. Physiol Rev 90, 23-46.

2. Malik VS, Schulze MB \& Hu FB (2006) Intake of sugarsweetened beverages and weight gain: a systematic review. Am J Clin Nutr 84, 274-288.

3. Bray GA, Nielsen SJ \& Popkin BM (2004) Consumption of high-fructose corn syrup in beverages may play a role in the epidemic of obesity. Am J Clin Nutr 79, 537-543.
4. Schulze MB, Manson JE, Ludwig DS, et al. (2004) Sugarsweetened beverages, weight gain, and incidence of type 2 diabetes in young and middle-aged women. JAMA $\mathbf{2 9 2}$, 927-934

5. Havel PJ (2005) Dietary fructose: implications for dysregulation of energy homeostasis and lipid/carbohydrate metabolism. Nutr Rev 63, 133-157.

6. Thuy S, Ladurner R, Volynets V, et al. (2008) Nonalcoholic fatty liver disease in humans is associated with increased plasma endotoxin and plasminogen activator inhibitor 1 concentrations and with fructose intake. J Nutr 138, 1452-1455.

7. Jurgens H, Haass W, Castaneda TR, et al. (2005) Consuming fructose-sweetened beverages increases body adiposity in mice. Obes Res 13, 1146-1156.

8. Tetri LH, Basaranoglu M, Brunt EM, et al. (2008) Severe NAFLD with hepatic necroinflammatory changes in mice fed trans fats and a high-fructose corn syrup equivalent Am J Physiol Gastrointest Liver Physiol 295, G987-G995.

9. de Moura RF, Ribeiro C, de Oliveira JA, et al. (2009) Metabolic syndrome signs in Wistar rats submitted to different high-fructose ingestion protocols. BrJ Nutr 101, 1178-1184.

10. Abdel-Sayed A, Binnert C, Lê KA, et al. (2008) A high-fructose diet impairs basal and stress-mediated lipid metabolism in healthy male subjects. Br J Nutr 100, 393-399.

11. Schulz KF, Altman DG, Moher D, et al. (2010) CONSORT 2010 Statement: updated guidelines for reporting parallel group randomised trials. BMJ 340, c332.

12. Lukaski HC, Johnson PE, Bolonchuk WW, et al. (1985) Assessment of fat-free mass using bioelectrical impedance measurements of the human body. Am J Clin Nutr 41, $810-817$

13. Machann J, Thamer C, Schnoedt B, et al. (2005) Standardized assessment of whole body adipose tissue topography by MRI. J Magn Reson Imaging 21, 455-462.

14. Machann J, Thamer C, Schnoedt B, et al. (2006) Hepatic lipid accumulation in healthy subjects: a comparative study using spectral fat-selective MRI and volume-localized ${ }^{1} \mathrm{H}-\mathrm{MR}$ spectroscopy. Magn Reson Med 55, 913-917.

15. Thamer C, Machann J, Bachmann O, et al. (2003) Intramyocellular lipids: anthropometric determinants and relationships with maximal aerobic capacity and insulin sensitivity. J Clin Endocrinol Metab 88, 1785-1791.

16. Mifflin MD, St Jeor ST, Hill LA, et al. (1990) A new predictive equation for resting energy expenditure in healthy individuals. Am J Clin Nutr 51, 241-247.

17. Brooks GA, Butte NF, Rand WM, et al. (2004) Chronicle of the Institute of Medicine physical activity recommendation: how a physical activity recommendation came to be among dietary recommendations. Am J Clin Nutr 79, 921S-930S

18. Matsuda M \& DeFronzo RA (1999) Insulin sensitivity indices obtained from oral glucose tolerance testing: comparison with the euglycemic insulin clamp. Diabetes Care 22, $1462-1470$.

19. Matthews DR, Hosker JP, Rudenski AS, et al. (1985) Homeostasis model assessment: insulin resistance and beta-cell function from fasting plasma glucose and insulin concentrations in man. Diabetologia 28, 412-419.

20. Livesey G \& Taylor R (2008) Fructose consumption and consequences for glycation, plasma triacylglycerol, and body weight: meta-analyses and meta-regression models of intervention studies. Am J Clin Nutr 88, 1419-1437.

21. Johnson RJ, Segal MS, Sautin Y, et al. (2007) Potential role of sugar (fructose) in the epidemic of hypertension, obesity and the metabolic syndrome, diabetes, kidney disease, and cardiovascular disease. Am J Clin Nutr 86, 899-906. 
22. Faeh D, Minehira K, Schwarz J, et al. (2005) Effect of fructose overfeeding and fish oil administration on hepatic de novo lipogenesis and insulin sensitivity in healthy males. Diabetes 54, 1907-1913.

23. Lê KA, Faeh D, Stettler R, et al. (2006) A 4-wk high-fructose diet alters lipid metabolism without affecting insulin sensitivity or ectopic lipids in healthy humans. Am J Clin Nutr 84, 1374-1379.

24. Stanhope KL, Schwarz JM, Keim NL, et al. (2009) Consuming fructose-sweetened, not glucose-sweetened, beverages increases visceral adiposity and lipids and decreases insulin sensitivity in overweight/obese humans. J Clin Invest $\mathbf{1 1 9}$, 1322-1334.

25. Lê KA, Ith M, Kreis R, et al. (2009) Fructose overconsumption causes dyslipidemia and ectopic lipid deposition in healthy subjects with and without a family history of type 2 diabetes. Am J Clin Nutr 89, 1760-1765.

26. Ngo Sock ET, Lê KA, Ith M, et al. (2010) Effects of a shortterm overfeeding with fructose or glucose in healthy young males. Br J Nutr 103, 939-943.

27. Sobrecases H, Lê KA, Bortolotti M, et al. (2010) Effects of short-term overfeeding with fructose, fat and fructose plus fat on plasma and hepatic lipids in healthy men. Diabetes Metab 36, 244-246.

28. Beck-Nielsen H, Pedersen O \& Lindskov HO (1980) Impaired cellular insulin binding and insulin sensitivity induced by high-fructose feeding in normal subjects. $\mathrm{Am} \mathrm{J}$ Clin Nutr 33, 273-278.

29. Rodin J, Reed D \& Jamner L (1988) Metabolic effects of fructose and glucose: implications for food intake. Am J Clin Nutr 47, 683-689.

30. Akhavan T \& Anderson GH (2007) Effects of glucose-to-fructose ratios in solutions on subjective satiety, food intake, and satiety hormones in young men. Am J Clin Nutr 86, $1354-1363$.

31. Johnson RJ, Perez-Pozo SE, Sautin YY, et al. (2009) Hypothesis: could excessive fructose intake and uric acid cause type 2 diabetes? Endocr Rev 30, 96-116.

32. Couchepin C, Lê KA, Bortolotti M, et al. (2008) Markedly blunted metabolic effects of fructose in healthy young female subjects compared with male subjects. Diabetes Care 31, 1254-1256.

33. Tran C, Jacot-Descombes D, Lecoultre V, et al. (2010) Sex differences in lipid and glucose kinetics after ingestion of an acute oral fructose load. Br J Nutr 104, 1139-1147. 